\title{
Mandatory retirement for gastroenterologists: A viewpoint
}

\author{
Alan BR Thomson MD PhD FRCPC ${ }^{1}$, Charles N Bernstein MD PhD FRCPC ${ }^{2}$, Des Leddin MD PhD FRCPC 3
}

\section{THE CASE AGAINST MANDATORY RETIREMENT \\ By Alan BR Thomson}

Through the course of our careers, some shorter and some longer, we have all experienced a most welcome decline in many workplace barriers, such as prejudice relating to sex, sexual orientation, ethnic background and religion. Sexual equality in medicine has benefitted both our profession and our patients. In academia, while equity has not uniformly been achieved, major steps are being made to provide the encouragement and adaptation of more flexible work conditions and promotion standards. Our society is making strides in the areas of racial equity and sexual orientation, and this has permeated through our medical profession. Progress is slow, but we have our civil rights, protected in the Canadian Bill of Rights, and with time, patience and people of good will, 'we shall overcome'.

Despite social progress, there remains one lasting workplace prejudice - age. The laws of the land state that you cannot express prejudice against a person based merely on his or her age. Defining age can be complex. Should the definition merely reflect a number of chronological years or, alternatively, a biological process reflecting a change in a persons' mental and physical prowess? From our own practices, we recognize the octogenarian who is a 'successful ager' and someone deserving of aggressive modern medicine. And then there are those who are 'old' in their fifth decade. Mental and physical capacities may decline at various rates in different people - there are senior physicians who may have forgotten more than some of us ever knew! In a procedure-oriented specialty such as gastroenterology, manual dexterity may decline in the advancing years, but again this is so highly variable, and does not suddenly deteriorate when the clock strikes three score and five years. Even if manual dexterity decreases, older physicians may capably contribute as consultants and teachers.

While it may be difficult to agree on the definition of 'aging', it is unfortunately all too easy to define 'ageism', discrimination against older persons. The Conference Board of Canada has recently stated, "Mandatory retirement is an anachronism. Age discrimination must be tackled to help ensure that older workers are not denied opportunities to work because of their age" (1).

What are some of the arguments for forced retirement? Impaired functioning, time to do something different, need to make room for younger folks? Some of our senior gastroenterology colleagues are even more productive now than they were in their more youthful times. Some hold Canadian Institutes of Health Research grants, publishing several papers a year, receiving teaching awards, and bringing maturity, wisdom, experience and mentoring to the profession. Where is the evidence that the productivity of academics falls with age, or that they are simply a cherished relic of our academic departments? But of course, there may be older clinicians - just as there may be younger clinicians - who should have retired years ago. The issue is performance, not age. If the annual reappointment process that many institutions have for active medical staff is sufficient to evaluate competence at age 45 , why is it not good enough at age 65 ? Special tests of competence for sexagenerians are prejudicial, unless they are applied to persons of all ages. The design of such assessment tools is difficult, but that difficulty does not justify prejudice.

At the level of the institution, it may be argued that compulsory retirement enhances their ability to plan. But few physicians choose to work into their later years, and already there is the uncertainty brought by early retirement, departures and death. At a personal level, planning for one's eventual retirement is important, channelling considerable intellect, enthusiasm and drive from our medical practices, to the development of other pursuits that are often postponed or denied due to the many years of commitment, dedication and focus on careers and patients. Life is all about choices. Some good choices and some bad. But what we choose to do in those senior years - and when and how we plan to do it - should be our choice. Protect our tenure, let us retire with dignity.

The third quietly whispered yet rogue justification for forced retirement is the need to capture the salary or the endoscopy/ward resources to use for younger clinicians. While it is important to bring on junior staff, is that any justification to take away what older physicians have spent years fostering? If it is acceptable for community practitioners to maintain their practices, why wouldn't it be so for academic physicians?

Perhaps for some of you with 15, 20 or even 25 years left in your work life, all of this talk about age prejudice and the right to work may seem to be totally irrelevant. Perhaps that is why, decades ago, some of us agreed to sign what were then obligatory clauses about compulsory retirement. Perhaps some of you will be sympathetic because age prejudice is illegal, immoral and senseless, particularly at a time when there is a shortage of physicians.

It might be of interest to know that mandatory retirement is forbidden in approximately one-half of the Canadian provinces. Many prestigious and enlightened Canadian universities have no mandatory retirement (University of Toronto in Toronto, Ontario; McGill University in Montreal, Quebec; Laval University in Quebec City, Quebec; the University of

${ }^{1}$ University of Alberta, Edmonton, Alberta; ${ }^{2}$ University of Manitoba, Winnipeg, Manitoba; ${ }^{3}$ Dalhousie University, Halifax, Nova Scotia

Correspondence: Dr ABR Thomson, University of Alberta, Division of Gastroenterology, Zeidler Ledcor Centre, 130 University Campus,

Edmonton, Alberta T6G 2X8. Telephone 780-492-6490, fax 780-492-7964, e-mail alan.thomson@ualberta.ca

Received and accepted for publication July 17, 2007 
Montreal in Montreal, Quebec; the University of Calgary in Calgary, Alberta; and recently, the University of Alberta in Edmonton, Alberta). Surely we can correct this individual university-based prejudiced policy without the pain, cost and delay of another appeal to the Supreme Court of Canada (2).

Unless we all become or remain resolved to help each other to provide warm and caring work environments, free from rudeness, harassment or prejudice, then we all suffer. By accepting the richness and benefits of our differences, by treating each and every one of us with respect and consideration, we grow stronger as professionals, our patients enjoy better care, and we will have the satisfaction of 'doing the right thing'. So, this is an issue of 'human rights', of dignity. This should be a matter of choice.

\section{THE CASE FOR MANDATORY RETIREMENT}

\section{By Charles N Bernstein}

In writing a commentary advocating for mandatory retirement I had to consider whether I was prepared to antagonize some of my older colleagues, many of whom are friends, some even good friends. Many of my sexagenarian colleagues seem as invigorated as ever and for many, mandatory retirement presents itself as a cruel response to long and productive careers. Hopefully, my argument will convince them that mandatory retirement might be the best offer their university has offered them in a long while.

Because those who are aging lose manual dexterity while retaining mental capacity, it was suggested that perhaps older physicians could contribute in other ways than in full gastroenterology practice. So, Dr Thomson approves of introducing a graduated age bias. Few could argue that a 65-year-old surgeon or endoscopist has similar manual dexterity and quickness as a 35-year-old. Is it ethical for even one patient to be put at risk because there are aging physicians who might be somewhat forgetful or less adroit with their hands? While Dr Thomson may be prepared to relinquish endoscopy, others of his birth cohort may not be so ready to do so. A mandatory 'manual procedure retirement' will lead to others writing 'opinion/editorial' pieces about the prejudice against the elderly doing procedures. After all, this is a group of sexagenarians that started adulthood during the 'ParticipACTION' program, went through mid-life with designer running shoes, and now has access to a variety of potent and selective inhibitors of cyclic GMP-specific phosphodiesterase type 5, facilitating extra minutes to hours of exercise weekly. Should universities really have to vet a physician's abilities selectively? Would it not be less prejudicial to simply state that at a given age, all must retire?

It was argued correctly, I might add, that many physicians regardless of age, are intellectually astute, curious and capable of delivering good health care. I doubt that mandatory retirement is accompanied by a mandatory ban of setting foot in the medical school. Mandatory retirement is accompanied by a loss of university salary and space to assess (and hence bill for) patients. Financially, this may be burdensome, but retiring physicians can often retain university appointments (Emeritus status) that could allow for ongoing research activities and access to university facilities. Physicians can leave the university to pursue practice or consulting opportunities in the private sector. In fact, they can retain a university appointment and take part in some of the mind-enhancing aspects of the university such as interactions with students, educational rounds and symposia, and research studies while earning their living in the community unencumbered by whatever restraints the university had placed on them during their clinical careers.

The benefits of being given time to spend away from the 'ivory tower', to explore new interests and enhance important family relationships were identified. Is this the university's paternalistic way of extracting some aging physicians who have been 'married' to their clinical practices or laboratories and reminding them that by age 65 , life becomes somewhat timelimited on opportunities outside of medicine? Many important posts within society have term limits, such as Department of Medicine Chair, Division of Gastroenterology Chief or United States President. Wise men and women some time ago decided that change is a necessary component to progress, facilitating renewal and fresh ideas. Mandatory retirement is a term limit of sorts.

Dr Thomson draws on society's usual prejudices to induce our indignation at this injustice toward the elderly. That is the beauty of mandatory retirement at age 65 . It shows no prejudice by sex, ethnic background, sexual orientation or any other prejudices that may come to mind. We would all be forced to retire at a specific age. While chronology and biology do not march in step in all humans, there are just some things 65-year-olds cannot do that 35-year-olds can (including late night calls) and physicians know this better than any other professionals.

If there was no mandatory retirement, those universities trying to engage in renewal would surely be accused of prejudice when a certain employee was 'encouraged' to retire. Furthermore, university faculty hiring and reimbursement are all limited within the envelope of funding that the universities have allotted for their faculties of medicine. It is never quite large enough and there is never enough money for proper salary reimbursement. Hence, if we allow our older physicians who on average will not and should not be more productive than our younger or middle aged physicians, to stay on indefinitely, the universities will lose access to salary lines to bring on new faculty. New faculty brings new ideas and the access to new faculty jobs brings hope and enthusiasm to our trainees.

It was also pointed out that many older physicians are intellectually vigorous, hold national grants and publish important findings in peer-reviewed journals. They induce awe and optimism among younger faculty and trainees, and contribute enormously to the reputation and grandeur of the universities in which they work. As these physicians face mandatory retirement, it behooves the university administration to find a creative way to maintain these gems within the university environment. However, in every university we are also familiar with some of our elders who are hanging on beyond their best years. They are facetiously referred to as 'fossils'. While many 'fossils' have great value, unfortunately some university faculty 'fossils' have long lost their value. The university community has long recognized this inevitability and a mandatory retirement is one of the university's more egalitarian tenets. If given the choice, how many hanger-ons would smell the smelling salts rather than the roses, be jolted into reality and retire?

In 20 years, I may be facing mandatory retirement. At my illustrious university (noticeably absent from Dr Thomson's list of leading institutions without mandatory retirement) we currently have no mandatory retirement. We need renewal. We need term limits. We need mandatory retirement. I would 
suggest we try it for 20 years and then revert back to an openended system and see what works best!

\section{By Des Leddin}

\section{A BALANCED SUMMARY}

In the preceding article, two gastroenterologists with a proven track record in clinical gastroenterology, research, administration and teaching presented the arguments for, and against, mandatory retirement at age 65 .

Dr Thomson made the point that mandatory retirement represents a form of age prejudice. He also questioned the definition of old, and asked whether this should be defined on a chronological or functional basis. He made the undeniable case that being older is not incompatible with being productive. Furthermore, he would argue that because the annual reappointment process assesses competence at all ages through a gastroenterologist's career, it ought to be satisfactory to measure competence at the final stage of a career.

Dr Bernstein presented the opposing viewpoint. He pointed out that mandatory retirement only applies to the university component of practice. There is nothing to stop an individual from continuing to work in the community if they so wish. He argued that change and renewal of the academic community is good and that there is a need to make room for newer clinicians and scientists to enter the academic stream to keep departments vigorous and productive.

Both arguments have elements of merit. As an impartial observer, one finds oneself becoming uncomfortable in trying to make a decision as to which perspective is correct. The debate has the flavour of an ethical dilemma in which there is no perfect answer. From an ethical perspective, there are a number of issues at work. Forcing mandatory retirement at age 65 does have implications of a value judgment. The implication is that a person in their older years is not as valuable as someone in their younger years. There is a major autonomy issue. Forcing someone to retire certainly does not respect their wish to continue to work. There is an aims aspect to this in that the department of medicine's, or university's, aim may be good from a departmental perspective in bringing new blood into a department, but it may conflict with the aim of the individual to continue to work and be productive in later years. There is really no truth issue here because everyone is being open and above board with the process.

In ethical terms then, three ethical principles are in conflict, namely the need to value all humans equally, the need to respect individual autonomy and finally, the need to ensure that the aim of an action is good and not harmful.

Complex issues that involve ethical conflicts are not easy to resolve. Prolonged discussions can lead to a greater understanding on the part of all parties involved, but it rarely leads to resolution of the conflict. In my opinion, it is likely that the lawyers will be the ones to make a decision regarding the issue of mandatory retirement. It seems likely that this issue will go to court in each of the provinces, or that the Supreme Court of Canada will be asked to adjudicate.

If the court rules that mandatory retirement is unreasonable, they likely will also recognize that there is a need to protect patients. This will lead to a much more vigorous annual, or biannual, credentialing process. This process will be far more rigorous than the current one and will likely involve tests of both cognitive and manual dexterity. These would be very difficult, but not impossible to design. It will be necessary, therefore, to design a recredentialing process, which is rigorous, evidence-based and defensible against the challenges that will inevitably come!

\section{REFERENCES}

1. Conference Board of Canada. Executive action: Canada's demographic revolution, adjusting to an aging population. March 2006:5.

2. Dickason v. University of Alberta, [1992] 2 S.C.R 1003. 


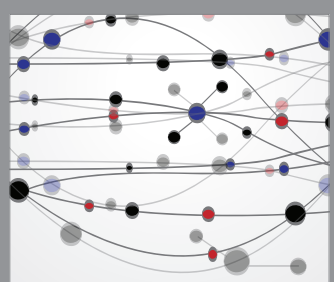

The Scientific World Journal
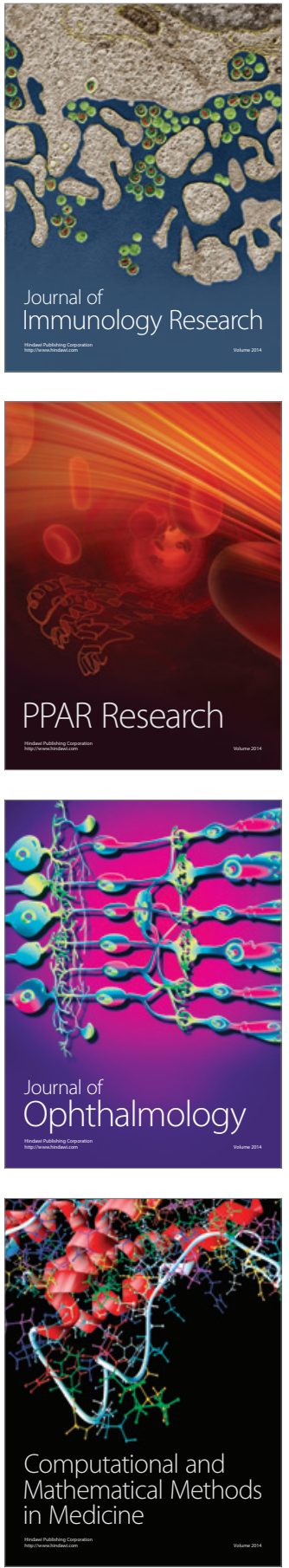

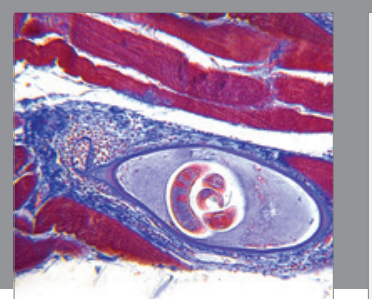

Gastroenterology Research and Practice

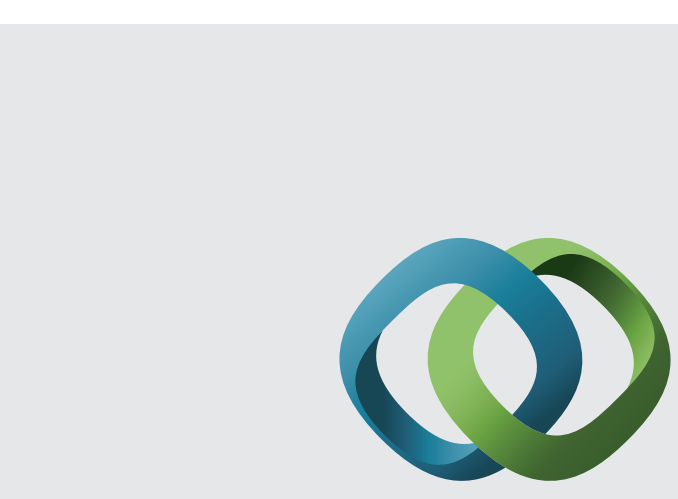

\section{Hindawi}

Submit your manuscripts at

http://www.hindawi.com
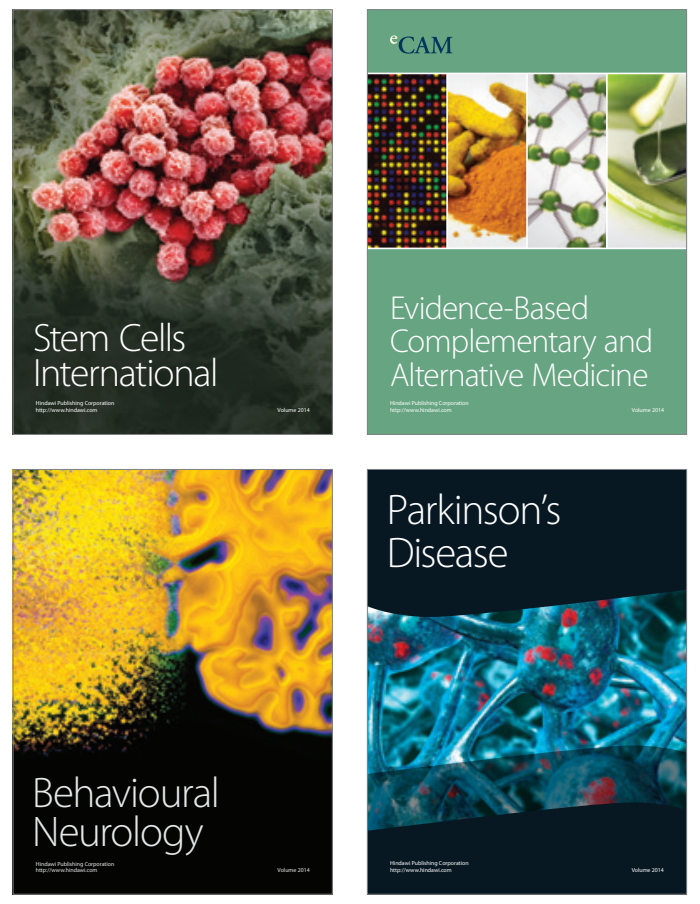
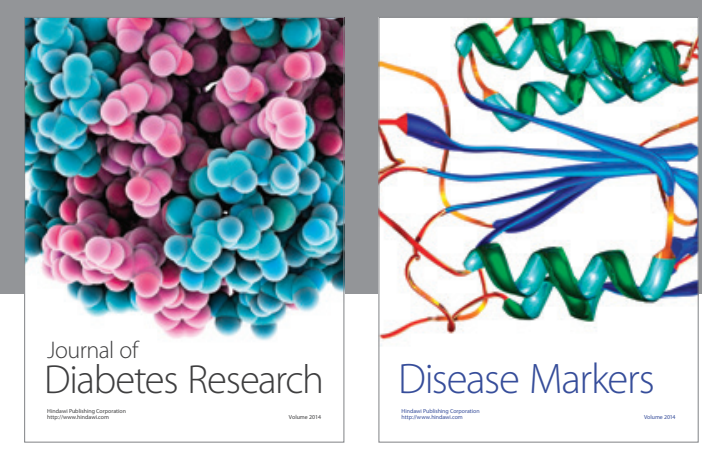

Disease Markers
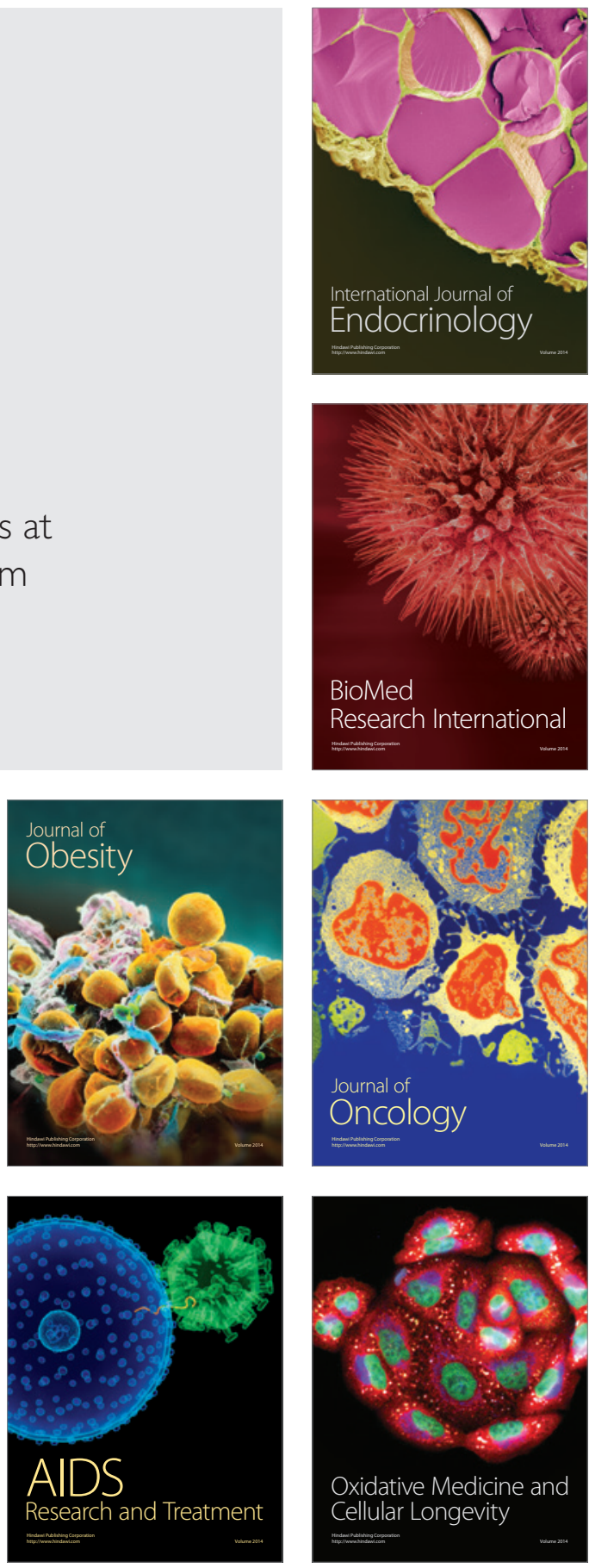